\title{
Ciência da Computação também é coisa de menina!
}

\author{
Karina Mochetti, Luciana Salgado, \\ Ana Valladares Zerbinato, Beatriz Lopes Souza, Meirylene Rosa Emidio Avelino
}

${ }^{1}$ Instituto de Computação - Universidade Federal Fluminense (UFF)

Niterói - RJ - Brazil

\{kmochetti, luciana\}@ic.uff.br

\{ana_zerbinato, beatrizls, meirylenerea\}aid.uff.br

\begin{abstract}
Resumo. A participação de mulheres nas áreas de Computação e Tecnologia da Informação é extremamente baixa. Tal fato é preocupante já que diversidade em qualquer ambiente é de vital importância para sua evolução, principalmente no cenário atual em que os usuários passaram de consumidores para produtores de tecnologias e conteúdos digitais. Esse trabalho descreve a atividade inaugural realizada por nós na Universidade Federal Fluminense (UFF) com os alunos recém-inscritos no curso de Ciência da Computação. O objetivo principal do evento era promover uma discussão sobre o que leva as meninas a escolherem ou (não) a área de tecnologia da informação e analisar a interação entre os alunos, principalmente com as meninas, nos primeiros dias de aula.
\end{abstract}

\begin{abstract}
Women's participation in Computer and Information Technology field is extremely low. This fact is disturbing since diversity in any environment is vital to a good development, especially in technology where the role of end users is changing and they have gone from consumers to producers. This paper describes our project's inaugural activity at Fluminense Federal University (UFF) with the newly enrolled students in the Computer Science course. Our goal was to promote a discussion about what makes girls to choose or not the information technology field and analyze the interaction among students, especially girls in the first days of school.
\end{abstract}

\section{Introdução}

A diversidade de profissionais em todas as áreas é fundamental para que seja possível representarmos todos os indivíduos da sociedade moderna e, portanto, termos soluções mais adequadas aos problemas por ela enfrentados. Diante desta afirmativa é preocupante o baixo número de mulheres atuando na área de Tecnologias da Informação. Segundo o PNAD, em 2009 somente 18,84\% dos profissionais de TI eram mulheres [10].

A dificuldade de inclusão de mulheres em ambientes dominados por homens não é um problema atual, e traz à tona fatores importantes como o papel da mulher na sociedade, cujas regras são impostas e criadas por homens [9]. Mais especificamente na área de TI, temos atualmente grandes congressos e grupos formados com o objetivo de estudar esse problema e tentar revertê-lo. Podemos citar, por exemplo, o congresso Grace Hopper Celebration of Women in Computing do Instituto Anita Borg [4] e a Association for Women in Mathematics [1]. 


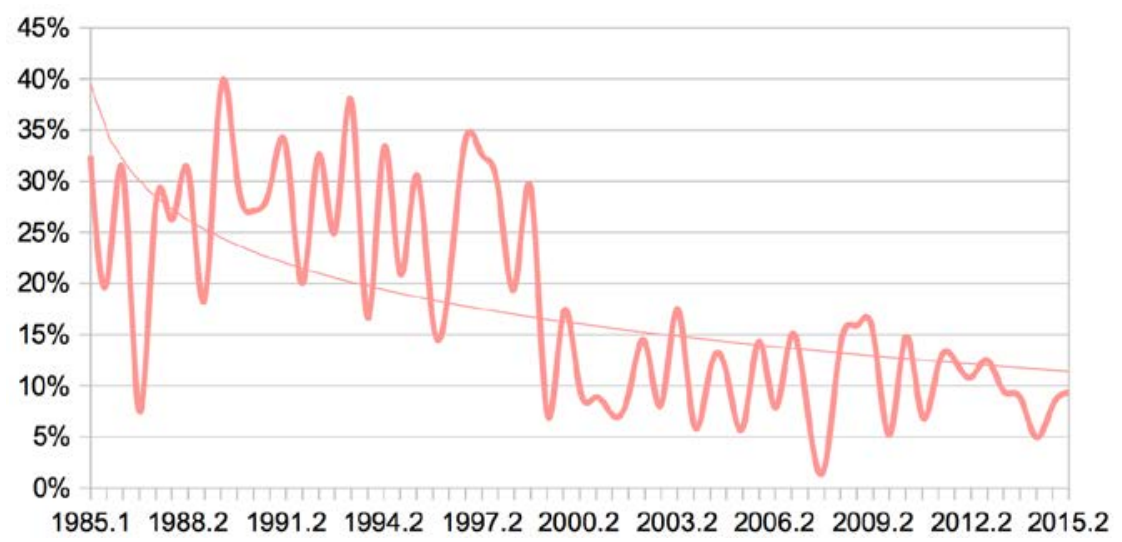

Figura 1. Gráfico de porcentagens de alunas nas turmas do curso de Ciência da Computação da Universidade Federal Fluminense (UFF).

Dentro desse contexto, diversos projetos nacionais foram criados, o principal deles sendo o Programa Meninas Digitais da Sociedade Brasileira da Computação (SBC) [6] sob coordenação dos professores Cristiano Maciel (UFMT) e Silvia Amélia Bim (UTFPR). Esse programa tem como objetivo motivar alunas do ensino médio e fundamental a seguir carreira na área de Tecnologias da Informação. Ele já possui algumas filiais regionais como o Meninas Digitais: Regional Sul [8], o Meninas Digitais: Regional Mato Grosso [7], o Emili@as [3] e o Cunhatã Digital [2], e recentemente uma filial no estado do Rio de Janeiro, o \#include $<$ meninas.uff $>$ [5].

Este artigo descreve a primeira pesquisa, e seus respectivos resultados, realizada no contexto do Projeto \#include $<$ meninas.uff $>$, do Instituto de Computação (IC) da Universidade Federal Fluminense (UFF).

\section{Objetivo}

Como primeira tarefa do Projeto \#include $<$ meninas.uff $>$, organizamos uma atividade com os alunos recém-inscritos no curso de Ciência da Computação da Universidade Federal Fluminense (UFF), no contexto do Evento de Acolhimento dos Calouros, promovido pelo Diretório Acadêmico do curso. Dos 70 alunos inscritos, somente 8 são meninas. Nosso principal objetivo era promover uma atividade para analisar qual seria o comportamento dos alunos com relação às novas alunas e promover um debate sobre o tema.

O curso de Ciência da Computação da Universidade Federal Fluminense (UFF) existe desde 1985. Hoje o curso tem em média 520 alunos matriculados e atualmente são oferecidas 140 vagas anuais para o ingresso duas vezes ao ano. Dos mais de 3000 alunos que já passaram pelo Instituto de Computação da Universidade Federal Fluminense (UFF), somente $16 \%$ eram mulheres. Nota-se, contudo, que esse número já pequeno diminuiu muito nos últimos anos, chegando a valores alarmantes como a inscrição de somente uma menina em 2008. A Figura 1 mostra um gráfico da porcentagem de meninas durante os 30 anos de curso.

Com base nessa grave estatística, nosso projeto pretende contribuir para que esse problema seja contornado, motivando alunas do ensino médio/fundamental a seguir carreira na área de Computação e emponderando as alunas de graduação e pós-graduação já inclusas na área. 


\section{Metodologia}

A atividade foi dividida em 3 partes principais, cada uma com o objetivo de analisar e avaliar ações e comportamentos diferentes dos alunos. Ao todo, participaram como observadoras da pesquisa cinco membros do Projeto \#include $<$ meninas.uff $>$ : duas professoras e três alunas da gradução.

Ainda na fase de recrutamento dos participantes, foi pedido aos organizadores do acolhimento que não avisassem os alunos que a atividade estaria relacionada com a questão da falta de mulheres nas áreas de tecnologia da informação. Primeiramente, os alunos participantes da atividade ( 37 no total, dos quais 5 meninas) foram posicionados num grande círculo na intenção de que cada um se apresentasse para todos os demais. Ao final desta etapa pedimos a alguns dos participantes que dissessem o nome de algum outro colega, selecionado por nós, pesquisadoras.

A segunda etapa foi uma dinâmica em grupo. Os alunos foram divididos em 5 grupos, com uma menina por grupo. A divisão foi feita dando-se um número para cada menina na frente de todos, enquanto cada garoto ao receber seu número deveria procurar a menina correspondente. Desta forma queríamos que as meninas tivessem a função indireta de liderança, sem que este tenha sido imposto diretamente por nós. O objetivo dessa dinâmica era que cada grupo desvendasse uma dica de uma caça ao tesouro feita baseada na Cifra de César [11]. A intenção dessa etapa era analisar como os grupos se organizariam e se as meninas manteriam (ou não) a posição de liderança.

A terceira e última etapa promoveu um debate aberto com os alunos sobre os motivos para um número cada vez mais baixo de mulheres na área de Tecnologias da Informação. Foi aberto um debate sobre o porquê esse número é tão baixo e as meninas tiveram a oportunidade de dividir histórias pessoais a respeito da sua decisão de cursar uma faculdade dominada por homens.

\section{Resultados}

Na primeira etapa da atividade ficou clara a posição de destaque que as meninas ocupam e a diferença do tratamento dado pelos colegas. No grande círculo de apresentação, as meninas se mantiveram sempre próximas umas das outras e na hora de se apresentar não só todos os meninos fizeram total silêncio prestando muita atenção, como elas foram as únicas a receber aplausos. No momento em que foi perguntado o nome dos alunos, a maioria não sabia o nome de todos, mas ao perguntarmos o nome das meninas os próprios alunos disseram "Ah! Obviamente todos irão lembrar os nomes das meninas!".

Esta parte da atividade nos deu evidências de como as meninas ganham destaque, querendo ou não, simplesmente por fazerem parte de uma minoria. Apesar de poder ser benéfico para algumas, isso pode ser um grande obstáculo para outras durante sua carreira, sabendo que sempre estão sendo observadas e analisadas por professores e colegas.

$\mathrm{Na}$ segunda etapa, os grupos foram divididos de forma que as meninas ficassem indiretamente numa posição de liderança. Elas davam nome aos grupos, elas tinham o número dos grupos e era responsabilidade dos meninos achá-las para formar seus grupos. No entanto, em nenhum momento nós verbalizamos que as meninas iriam liderar ou coordenar os grupos. Nesta fase observamos como a dica (escrita em um pedaço de papel) rapidamente foi tirada da mão das meninas. Em um grupo, apesar de ter sido en- 
tregue para a menina, um menino logo interferiu, segurando o papel ele mesmo sem que a menina sequer tocasse. Na maioria dos grupos não houve uma liderança propriamente dita, mas das cinco meninas, podemos dizer que três mantiveram essa posição durante a atividade.

$\mathrm{Na}$ etapa final os alunos foram convidados a compartilhar posições e experiências sobre os motivos de atualmente haver tão poucas mulheres na computação e esse número estar cada vez menor. Essa parte foi a mais rica de toda a atividade com grande participação tanto dos meninos quanto das meninas.

As opiniões foram dadas livremente e sem uma ordem pré-determinada de quem falaria primeiro. Observamos que tanto meninos quanto meninas se interessaram em dar suas opiniões sobre o tema apresentado. Um dos alunos comentou: "Provavelmente essa é a primeira vez que alguns meninos estão ouvindo e conversando sobre esse assunto". Para as meninas foi claramente muito bom poder dividir um pouco das suas experiências e medos com outros alunos. Elas nos contaram que há uma cobrança da sociedade para que elas não façam cursos dominados por homens, com familiares e amigos as alertando para o problema de ser um curso "para homens" e as incentivando a fazer um curso na área de humanas. Elas também reclamaram da falta de exemplos de mulheres engenheiras e na área de exatas com uma delas deixando claro como a mãe dela, engenheira mecânica, foi uma grande influência e incentivo para que ela entrasse num curso de exatas.

Também foi compartilhado o medo e receio que elas têm principalmente durante os primeiros dias de aula com os trotes e as atividades de acolhimento. Elas disseram que procuram logo outra menina e se sentem mais seguras próximas umas das outras. Esse fato pode ser confirmado já que durante toda a atividade as meninas estavam sempre que possível num grupo próximas umas das outras e nunca divididas entre os meninos.

Após os depoimentos das meninas, alguns meninos comentaram que nunca haviam considerado a posição deles no curso. Um dos alunos chegou a dizer que agora eles ocupavam uma posição de opressor, mesmo que a maioria fosse oprimida no ensino médio por ser mais estudioso ou por qualquer outra característica, agora eles são os opressores das meninas por estarem em maioria. Segundo ele era preciso "prestar atenção no machismo que a gente comete sem perceber". Um outro aluno disse achar que "as mulheres são interessadas naturalmente por humanas" já que em Portugal, onde ele estudou, há aulas de programação no ensino médio e isso não aumentou o número de meninas na computação. Isso logo foi discordado pelas meninas e por grande parte dos meninos presentes na discussão.

\section{Conclusão}

A primeira atividade organizada pelo Projeto \#include $<$ meninas.uff $>$ mostra como é importante um trabalho não só com as mulheres, mas também com os homens. Criar um debate com grande participação masculina pode ajudar na conscientização deles do papel de opressor que eles têm como maioria, o que pode contribuir para a diminuição da hostilidade no meio, atraindo mais meninas e, principalmente, reduzindo o número de desistências por parte das alunas. Adicionalmente, tivemos inúmeras evidências verbais do quanto as meninas são desmotivadas pela sociedade (inclusive pela família) a procurar carreira na área de exatas. Como trabalhos futuros pretendemos estender esta investigação com as alunas já veterenas do curso de Ciência da Computação. 


\section{Referências}

[1] Association for Women in Mathematics.

sites.google.com/site/awmmath.

[2] Cunhatã Digital.

www. facebook.com/cunhantadigital.

[3] Emili@as.

https://www.facebook.com/emiliasarmacaoembits.

[4] Grace Hopper Celebration of Women in Computing.

ghc.anitaborg.org.

[5] \#include $<$ meninas.uff $>$.

Www. facebook. com/include.meninas.uff.

[6] Meninas Digitais.

sbcmt . wordpress.com/meninasdigitais/.

[7] Mulheres Digitais: Regional Mato Grosso.

www. facebook.com/MeninasDigitaisMT.

[8] Mulheres Digitais: Regional Sul.

www. facebook.com/meninasdigitaisufsc/.

[9] Simone de Beauvoir. O Segundo Sexo. Nova Fronteira, 1949.

[10] Bárbara Geraldo de Castro. Afogados em contratos : o impacto da flexibilização do trabalho nas trajetórias dos profissionais de TI. PhD thesis, UNICAMP, 2013.

[11] Dennis; Gordon Prichett Luciano. Cryptology: From caesar ciphers to public-key cryptosystems. The College Mathematics Journal, 18, 1987. 